\title{
A Praxis da Ecologia de Saberes: entrevista de Boaventura de Sousa Santos ${ }^{1}$
}

\author{
Fernando Ferreira CARNEIRO² \\ Noemi Margarida KREFTA ${ }^{3}$ \\ Cleber Adriano Rodrigues FOLGADO ${ }^{4}$
}

Falar de saúde das populações do campo, da floresta e das águas é falar da luta contra um modelo de desenvolvimento que considera essas populações invisíveis ou um empecilho para o "progresso". Na primeira década do século XXI o Brasil vive um processo de reprimarização de sua economia, fazendo com que as comodities minerais e agrícolas passem a representar a maior parte de tudo o que é exportado. Os movimentos sociais do campo brasileiro vêm denunciando esse modelo neodesenvolvimentista, pois vem impedindo o cumprimento da função socioambiental da terra e a realização da reforma agrária, promovendo a exclusão e a violência, impactando negativamente também nas cidades, agravando a dependência externa e a degradação dos recursos naturais.

No campo do pensamento crítico vários intelectuais tem-se aliado aos movimentos sociais no sentido de construir pontes para juntos buscarem alterar esse quadro. Um dos expoentes desse pensamento é o Professor Boaventura de Sousa Santos, do Centro de Estudos Sociais, da Universidade de Coimbra.

Santos $^{1}$ formulou um pensamento denominado "Epistemologias do Sul", a partir do qual se constata que o domínio desses modelos de desenvolvimento passam também pela ciência, que serve para reforçar todo o processo de invisibilidade e opressão que essas populações vem sofrendo. Como uma das propostas para romper com essa monocultura de um só saber está a Ecologia de Saberes, que valoriza os outros saberes produzidos pela luta dos oprimidos a esse modelo.

Nessa entrevista buscamos entendermelhor esse conceito, principalmente as questões relacionadas a sua prática. A pergunta inicial foi feita em Fortaleza - CE, no dia 24 de outubro de 2013, durante

1 Boaventura de Sousa Santos é professor catedrático jubilado da Faculdade de Economia da Universidade de Coimbra (Portugal), Distinguished Legal Scholar da Faculdade de Direito da Universidade de Wisconsin-Madison (EUA) e Global Legal Scholar da Universidade de Warwick (Reino Unido). É igualmente diretor do Centro de Estudos Sociais da Universidade de Coimbra; coordenador científico do Observatório Permanente da Justiça Portuguesa e membro do Núcleo Democracia, Cidadania e Direito (Decide).

2 Fernando Ferreira Carneiro é Professor Adjunto da Universidade de Brasília, do Departamento de Saúde Coletiva /Núcleo de Saúde Pública, coordenador do Observatório da Política Nacional de Saúde Integral das Populações do Campo e da Floresta - Teia de Saberes e Práticas

3 Noemi Margarida Krefta é Integrante do Movimento de Mulheres Camponesas; representante no Grupo da Terra; participante do Grupo Gestor do Observatório da Política Nacional de Saúde Integral das Populações do Campo, da Floresta e das Águas

4 Cléber Folgado é graduando em Direito pela Universidade Estadual de Feira de Santana - UEFS e membro da Direção Nacional da Via Campesina e do Movimento dos Pequenos Agricultores - MPA. Coordenação Nacional da Campanha Permanente Contra os Agrotóxicos e Pela Vida. 
o Encontro Internacional de Ecologia de Saberes: Construindo o Dossiê Sobre os Impactos dos Agrotóxicos na América Latina. As questões seguintes foram agregadas à entrevista posteriormente, no dia 19 de maio de 2014, as quais foram realizadas por membros ${ }^{3,4}$ do Observatório da Política Nacional de Saúde Integral das Populações do Campo, da Floresta e das Águas (OBTEIA) .

\section{CARNEIRO - Caro Boaventura, quais são os cuidados para a prática da Ecologia de Saberes?}

BOAVENTURA - A ecologia de saberes é um conceito que visa promover o diálogo entre vários saberes que podem ser considerados úteis para o avanço das lutas sociais pelos que nelas intervêm. É uma proposta nova e, como tal, exige alguns cuidados. Como é nova, o caminho faz-se ao caminhar. Não há receitas de nenhuma espécie. Quais são os principais cuidados? Em primeiro lugar, a ecologia de saberes não se realiza nos gabinetes das universidades ou nos gabinetes dos líderes dos movimentos. Ela se realiza em contextos de diálogo prolongado, calmo, tranquilo, como são as oficinas da UPMS, da Universidade Popular dos Movimentos Sociais, para que permitam que mais vozes surjam, que aquelas vozes mais tímidas e até inaudíveis se manifestem e que, portanto, o ambiente seja suficientemente inclusivo e acolhedor para que a diversidade de conhecimentos poder emergir. Portanto, em primeiro lugar, a ecologia de saberes é um processo coletivo de produção de conhecimentos que visa reforçar as lutas pela emancipação social.

Em segundo lugar, é um processo algo anárquico, que não tem e não deve ter líderes embora possa ter facilitadores da discussão. Quando digo anárquico quero dizer realmente democrático. É uma construção democrática de conhecimento, onde os processos não se distinguem dos conteúdos. Processos democráticos de construção de conhecimento democrático. Portanto, se é preciso mais tempo para democratizar o conhecimento, então, leva-se mais tempo. Se não é possível fazer uma carta, um pronunciamento, porque não se chegou a um acordo, não há crise nenhuma. A ecologia dos saberes, como grande processo democrático, exige paciência.

Depois, é preciso evitar dois riscos frequentes. Primeiro, no que diz respeito aos cientistas sociais, gente que circula nos âmbitos acadêmicos. Por vezes, cientistas comprometidos, que investiram muito em suas carreiras para produzir uma ciência solidária com as lutas sociais e que até sofreram as consequências disso, porque as universidades conservadoras não apreciaram sua orientação e seu trabalho, quando chegam às instâncias de produção da ecologia de saberes têm uma grande ânsia de mostrar que estão certos e que o seu conhecimento pode ajudar muito. A pior coisa é um cientista que quer ajudar a todo o custo, porque esse normalmente quer ajudar nos seus próprios termos. E as pessoas e os movimentos querem ser ajudados nos seus termos, ou seja, entre-ajuda, mutirão. A ecologia dos saberes é uma minga, como dizem os indígenas latino-americanos, é um mutirão, constrói-se coletivamente. Então, a primeira coisa é que esses cientistas têm que saber escutar, e não apenas falar. Saber escutar profundamente é um dos princípios básicos da ecologia dos saberes

Nas oficinas da UPMS temos para todos a recomendação de que nunca se deve falar muito de 
cada vez. E convencionamos fazer um gesto que tem sido muito eficaz: à medida que os presentes vão achando que alguém está a falar demasiado vão levantando a mão e abanando-a. Recentemente na UPMS que realizámos na Bolívia, um grande líder indígena, amigo meu, Tomás Huanacu, da Conamaq, começou a falar e, entusiasmado, esqueceu-se do tempo. Começou uma mão a levantarse e a abanar, depois outra, depois eram 30 mãos e ele teve de parar de falar. Então, é uma maneira simples de criarmos democracia nas discussões.

Mas os cientistas, os intelectuais, têm certa propensão a falar mais e, sobretudo, a não escutar, ou porque já viram "tudo" no trabalho de campo, ou porque conhecem os temas em discussão ou não os consideram muito relevantes. Às vezes são capazes de olhar para o celular e mandar mensagens enquanto um líder do movimento está a falar.

Há uma série de metodologias próprias para quem está a coordenar. Não pode haver líder, mas deve haver coordenação, facilitadores. É o que nas oficinas da UPMS chamamos de acordo de convivência.

Por outro lado, há o risco dos movimentos. Primeiro, porque temos de fazer uma distinção entre ativistas e líderes. Há muito líder que é um intelectual orgânico, no sentido gramsciano. Ele ou ela tem conhecimentos científicos, às vezes são universitários, e na presença dos cientistas ou intelectuais querem ser ainda mais cientistas ou intelectuais. E por vezes calam aqueles que não têm essa capacidade de falar. Portanto, é muito bom que, na escolha das sessões onde se constrói a ecologia de saberes, haja um cuidado para que os participantes dos movimentos sociais não sejam todos universitários dos movimentos.Devido à democratização da universidade já há hoje muito líder comunitário com curso universitário. No polo oposto pode haver participantes que não dominam bem a lingua veicular dos diálogos. Pode ser necessária a tradução para que cada um ou cada uma se expresse na língua que domina melhor. Isto acontece frequentemente nas oficinas ou sessões de ecologia de saberes em que participam povos indígenas.

O outro é o cuidado fundamental de não ocultar as divergências que existem entre os diferentes movimentos e organizações. Há por vezes muitas diferenças entre eles. As diferenças não vêm apenas de uns deixarem se corromper pela lógica agroindustrial. Há uma dimensão política. Uma dimensão que vem do fato de haver divergências de fundo entre os diferentes setores populares. Um setor urbano não tem a mesma concepção da terra que um setor camponês. Um setor camponês não tem a mesma concepção que um setor indígena. Nós temos hoje conflitos no continente, muito fortes, entre indígenas, indígenas mineiros, indígenas cocaleros e indígenas camponeses. Precisamente porque alguns querem avançar com a exploração da terra e com a agricultura, admitem utilizar agrotóxicos para competir com a grande indústria. Portanto, isso cria conflitos grandes, e esses conflitos precisam ser tratados.

A ecologia de saberes não é uma estratégia epistemológica ou política para dialogar com o inimigo, com os opressores, mas para criar força entre os oprimidos. Ou seja, para lidar com o 
que o Mao Tse Tung chamava de contradições secundárias, contradições no seio do povo, por exemplo, entre trabalhadores industriais e camponeses ou entre estes e indígenas. Todos pobres, todos tentando sobreviver e lutar com dignidade, mas com diferenças. E, portanto, elas têm que ser muito discutidas e nem sempre é fácil que isso ocorra.

Por último, penso que há uma dificuldade muito grande: a atitude a tomar perante o conhecimento científico. Vivemos em um mundo onde a ciência tem grande hegemonia. Ela apresenta-se como um saber homogêneo mas em verdade é internamente muito diversificado. Os movimentos têm de conhecer essa diversidade e explorá-la a seu favor. Por exemplo, fraturar a ciência, entre a que trabalha para os agrotóxicos e a que trabalha contra os agrotóxicos. Esta última é nossa aliada e, com base na ecologia de saberes podemos fazer com que ela dialogue com saberes populares, camponeses, indígenas, urbanos, etc. Mas neste domínio as dificuldades são acrescidas porque cada movimento tem sua autonomia, para se organizar, ver quais são suas estratégias. Tudo isso é realpolitik. Os movimentos têm suas estratégias, suas articulações políticas. Podem ter interesses que de alguma maneira não lhes permitam fazer alianças com outros grupos. É um mundo muito minado por contradições.

São contradições que, como digo, não obrigam a uma guerra civil, que se podem resolver pelo diálogo, mas exigem que todos os movimentos e todos os cientistas envolvidos sejam tradutores interculturais todo o tempo e com uma paciência enorme. E nunca ter obsessão de resultados.

Venho de uma UPMS da Bolívia que foi a coisa mais extraordinária que eu vivi recentemente. O contexto apontava para um processo político muito complexo, de muitos movimentos sociais totalmente fraturados, precisamente por causa da política do Presidente Evo Morales que tem dividido muito os movimentos sociais, indígenas, camponeses. Terminamos a oficina da UPMS com líderes de facções opostas abraçando-se, buscando o reencontro. A fala que mais me impactou foi: "Estão tentando nos dividir, temos que nos reencontrar."

Há uma outra precaução a ter. Quando iniciamos um qualquer processo diálogo centrado num tema (terra, saúde, direitos humanos) tendemos a juntar apenas os movimentos e cientistas que trabalham especificamente nessa área. E isso é um convite ao fracasso. É preciso trazer outros movimentos e outros saberes transversais. Por exemplo, a minha experiência diz-me que a participação dos movimentos de mulheres é fundamental.As activistas de movimentos de mulheres que participaram recentemente em UPMSs na Bolívia em Moçambique sobre questões de terra tiveram uma posição extremamente importante ao afirmarem publicamente que a luta pela terra não era apenas uma luta de camponeses ou de indígenas. Era também uma luta das mulheres.

Do mesmo modo, saúde é demasiado importante para ser deixada apenas aos cientistas e técnicos da saúde e aos movimentos sociais e da Educação Popular e da Saúde. Tem que ser incluídos muitos outros saberes. 
CARNEIRO - Quais foram as contribuições do pensamento marxista (não ortodoxo) e de Paulo Freire para a formulação das "Epistemologias do Sul”?

BOAVENTURA - Considero-me marxista e remeto sempre quem me faz esta pergunta para o que escrevi há mais de vinte anos em Pela Mão de Alice. Marx continua a proporcionar-nos a crítica mais convincente e emancipadora do capitalismo enquanto modo de produção. Mas como tenho sempre defendido, o capitalismo actua sempre em articulação com o colonialismo e o patriarcado. Ora a análise marxista destes dois modos de dominação é muito insuficiente e, por vezes, equivocada ou totalmente ausente. Daí a necessidade de repensar o marxismo e o articular e mesmo enriquecer com outras tradições críticas, das feministas às poscoloniais. Ser marxista hoje exige imaginação crítica assente na seguinte inquietação: que teoria produziria hoje Marx a partir das suas permissas mas tendo em atenção mais de um século de lutas sociais? Procurar enriquecer o marxismo com outras tradições críticas é ser fiel a Marx num sentido mais profundo. É fazer como Marx fez. É sabido que para formular a sua teoria Marx se inspirou em três tradições teoricas: a filosofia alemã, o socialismo utópico francês e a economia política inglesa. Só um dogmatismo estreito nos impede de seguir as suas pisadas adaptadas ao nosso tempo. Esse dogmatismo tem levado alguns dos nossos melhores intelectuais a declararem-se não marxistas para não continuarem a ser considerados traidores ou reformistas. Veja-se o caso do grande intelectual ecuatoriano de quem tive o privilégio de ser muito amigo, Bolivar Echeverria. Os marxistas teóricos sempre se viram como intelectuais de vanguarda. Eu vejo-me como intelectual de retaguarda, um facilitador da articulação entre movimentos sociais.

Quanto a Paulo Freire, a sua influência nas epistemologias do sul é muito importante. A pedagogia do oprimido continua a ser a melhor proposta de educação popular do século XX. Lembro que o meu primeiro estudo sociológico, a minha dissertação de doutoramento nos EUA se intitulou o "direito dos oprimidos". Mas tal como faço com Marx a melhor maneira de ser fiel a Paulo Freire é imaginar o que ele pensaria hoje sobretudo depos do Forum Social Mundial que marca o início do século XXI nas lutas sociais. Dois factores novos nos movem. Por um lado, a globalização, tanto a hegemônica como a contra-hegemônica que só muito tarde entrou no pensamento de PF, como facilmente se explica. Por outro lado, vivemos hoje num mundo de reconhecida diversidade cultural mobilizada por movimentos sociais que, longe de serem analfabetos, são extremamente cultos a respeito dos conhecimentos que provêm das suas culturas e das suas lutas. A dialética não é mais entre saber e ignorância mas antes entre saberes distintos onde todos aprendem ensinando e, portanto, onde todos são educadores. A ecologia dos saberes e a tradução intercultural são os instrumentos que eu proponho para continuar Paulo Freire. Tal como acontece com Marx, o problema hoje só existe na cabeça dos freirianos dogmáticos.

FOLGADO - Para além da UPMS você teria outros exemplos da aplicação das Epistemologias do Sul?

BOAVENTURA - Tenho vindo a fazer um enorme esforço para consolidar a proposta da ISSN 1982-8829 Tempus, actas de saúde colet, Brasília, 8(2), 331-338, jun, 2014// 
Universidade Popular dos Movimentos Sociais, por pensar que é uma filosofia e uma metodologia muito criativa para reforçar as energias emancipatórias ao centrar-se no interconhecimento entre saber acadêmico ou científico e saber popular e entre diferentes saberes populares protagonizados por diferentes movimentos sociais. A UPMS surgiu no FSM e durante anos localizou-se na América latina. Nos últimos anos conseguimos ampliá-la e estendê-la a outros continentes: à Africa onde realizámos três oficinas, à India onde realizámos uma oficina e à Europa onde realizamos duas oficinas. A avaliação que faço é muito positiva porque a proposta da UPMS tem-se revelado muito dinâmica e tem criado formas de intervir mais fortemente no espaço público. A limitação da UPMS tem sido a de que a enorme riqueza das interacções ficam circunscritas aos que nela participam nas oficinas. Como superar isso? Por exemplo, nas oficinas de Leiria (Portugal), Alcalá de Henares (Espanha) e Tunis (Tunisia) foram redigidas cartas aos europeus, nos dois primeiros casos, e cartas da dignidade, no último caso. A ideia foi divulgar ao máximo as cartas. Nas oficinas de Moçambique (sobre terra e extractivismo) optámos por fazer uma conferência de imprensa no final da oficina que teve grande repercussão graças ao empenhamento do Fórum Mulher. Na oficina de Brasília, os movimentos organizaram uma sessão pública com a Comissão dos Direitos Humanos do Ministério da Justiça. Na oficina da Bolivia, produziu-se um documento final que foi publicado em toda a imprensa graças ao empenhamento da Coordenadora das organizações de mulheres. $\mathrm{Na}$ mais recente, em Abril passado, em Quito, preparou-se um documento intitulado, na tradição indígena, "mandato" para ser amplamente divulgado pelos movimentos.

Mas obviamente, as oficinas da UPMS são um entre muitos outros instrumentos para fortalecer os conhecimentos nascidos na luta, que são essenciais às epistemologias do sul. No projecto alice (www.alice.ces.uc.pt) estamos sobretudo tentando criar formas de conhecimento assentes em instrumentos não escritos, ou seja, no reforço da oralidade, que corresponde mais genuinamente aos saberes populares. Ao mesmo tempo procuramos com a oralidade desmonumentalizar o saber científico. Veja por exemplo as Conversas do Mundo-longas conversas entre mim e intelectuais, líderes políticos, líderes de movimentos sociais-- e outras produções em vídeo no âmbito do projecto Alice.

FOLGADO - Tendo a Ecologia de Saberes como instrumento de diálogo entre os oprimidos, na busca por compreender suas diferenças e não fazer disso elementos de fragmentação, mas sim de acúmulo de força contra todas as formas de opressão, é possível afirmar que existe a prática da ecologia de saberes já sendo realizada pelos movimentos sociais, ainda que talvez não "batizem" tal prática como ecologia de saberes? Se sim, onde você mais tem visto isso e como se manifesta?

BOAVENTURA - O conceito de ecologia de saberes visa precisamente valorizar os diálogos entre movimentos sociais e entre eles e o conhecimento acadêmico progressista mas distante porque encerrado nas universidades e nos projectos de pesquisa. $\mathrm{O}$ conceito decorreu da minha experiência com movimentos sociais depois do FSM. Verifiquei que o problema não era apenas a distância entre o saber acadêmico e o saber popular. Era também a distância entre os saberes, 
conceitos, linguagens dos diferentes movimentos sociais, o que dificultava a a articulação nas lutas concretas. Por exemplo, uns falavam de emancipação e outros de libertação; uns tinham por objetivo os direitos humanos e outros a dignidade; uns falavam de terra e outros de território; uns defendiam a igualdade entre mulher e homem e outros a complementaridade igualitária. E por aí adiante.Acresce que estas diferenças eram e são fonte de equivocos e preconceitos que dividem os movimentos e os impedem de se unirem am lutas concretas. Esta desunião contrasta cada vez mais com a forte unidade multinacional do neoliberalismo.

FOLGADO - Em geral o que é novo traz certo nível de apreensão, e às vezes até de resistência e negação. Frente a isso, nosso questionamento é se existem resistências ao conceito "ecologia de saberes" e como as organizações sociais, em especial da Via Campesina que é uma das maiores articulações camponesa do mundo, tem se posicionado frente a tal conceito?

BOAVENTURA - Compreendo inteiramente as resistências ao uso do conceito. Elas decorrem de duas razões principais. Por um lado, o termo ecologia, que no conceito de ecologias de saberes expressa a ideia de convivência harmoniosa entre os saberes distintos dos distintos grupos sociais oprimidos, explorados e discriminados, pode induzir a ideia errada que o conceito dá prioridade às lutas e aos movimentos ecológicos sobre os restantes. Obviamente isso não verdade. Por outro lado, para uma certa tradição marxista mais ortodoxa a ideia de valorizar outros saberes que não o conhecimento marxista é suspeita de reformismo.

Como tenho dito muitas vezes, o importante é a ideia subjacente ao conceito de ecologia de saberes e não o conceito em si mesmo. Além disso o conceito tem um encaixe académico que pode não ser muito útil aos movimentos na prática de luta. Por isso, se se prefere falar de diálogo entre saberes não tenho qualquer objeção antes pelo contrário. $\mathrm{O}$ importante é termos em mente que não basta o diálogo. É preciso retirar dele força organizativa e de articulação entre movimentos para as lutas sociais que serão cada vez mais arriscadas para os movimentos isolados.

FOLGADO - Ao longo desses anos do conceito, tendo-o como processo em permanente construção, o que apontaria como desafio ainda a se construir no processo da ecologia de saberes?

A ideia da ecologia dos saberes é ainda uma ideia embrionária e muito minoritária. Tem muito para caminhar e só caminha a partir da experiência.

KREFTA - Como podemos aproximar a academia ou o saber acadêmico com o saber popular e cientifico das populaçoes do campo, floresta e das águas, falo porque na grande maioria das universidades o saber dessas populaçoes é tido como atrasado e sem valor.

BOAVENTURA - A UPMS e toda a reflexão epistemológica e teórica que tenho vindo a fazer vai no sentido de ultrapassar o preconceito universitário. A UPMS é um desses instrumentos e não 
$338 / /$

é por acaso que insistimos em usar o termo Universidade apesar de na UPMS fazermos o oposto do que fazem as univeridades convencionais. O nosso objetivo foi ocupar o termo numa disputa de hegemonia. A UPMS visa precisamente levar os universitários a discutirem com não universitários em contextos não universitários e em trazer os conhecimentos e conhecedores não universitarios para dentro da universidade convencional. É o que eu chamo a extensão ao contrário. Fazer a contra-universidade tambem dentro da universidade. 